九州大学学術情報リポジトリ

Kyushu University Institutional Repository

\title{
Application of Mixture of Fly Ash and Topsoil for Rehabilitation in Open-Pit Coal Mines in South East Asian Countries
}

Hamanaka, Akihiro

Department of Earth Resources Engineering, Faculty of Engineering, Kyushu University : Assistant Professor

Matsumoto, Shinji

Department of Earth Resources Engineering, Faculty of Engineering, Kyushu University

MURAKAMI, Kai to

Department of Earth Resources Engineering, Faculty of Engineering, Kyushu University

Shimada, Hideki

Department of Earth Resources Engineering, Faculty of Engineering, Kyushu University : Professor

他

http://hdl. handle. net/2324/4355476

出版情報: Land Reclamation in Ecological Fragile Areas : Proceedings of the 2nd International Symposium on Land Reclamation and Ecological Restoration (LRER 2017), pp.233-237, 2017-07-19. CRC Press

バージョン：

権利関係: 


\title{
Application of Mixture of Fly Ash and Topsoil for Rehabilitation in Open-Pit Coal Mines in South East Asian Countries
}

\author{
A. Hamanaka, S. Matsumoto, K. Murakami, H. Shimada \& T. Sasaoka \\ Department of Earth Resources Engineering, Kyushu University, Fukuoka, Japan
}

ABSTRACT: Rehabilitation of post-mine land in open-pit coal mines is necessary for sustainable development of coal. Although topsoil containing much nutrition should be secured for plant growth, there was the shortage and the erosion of topsoil by heavy rain in the tropical climate, especially in South East Asian countries. Therefore, in this study, the application of fly ash (FA) to topsoil was evaluated in terms of the growth of plants with Acacia mangium, aiming at securing topsoil in open-pit coal mines. As the result of the plant experiment, the inhibition of plant growth attributing to the dissolution of aluminum (Al) from FA was observed. The growth rate of the plants was decreased at the mixing ratio of more than $40 \%$ of FA. Thus, topsoil can be secured by mixing FA in topsoil in consideration of the mixing ratio, contributing to the successful rehabilitation of post-mine land in open-pit coal mine.

\section{INTRODUCTION}

\subsection{Rehabilitation in coal mining}

Rehabilitation of post-mine land is necessary for sustainable development of coal. Coal is mined with the destruction of surface structure, such as forest and grasses, in open-pit coal mining. Thus, rehabilitation of post-mine land is required at the end of the development of coal for environmental conservation. In open-pit mining, topsoil, which is formed from the surface down to approximately $1.0 \mathrm{~m}$ depth, is stored during the excavation of coal, followed by the placement in surface layer in post-mine land during rehabilitation since they contain much nutrition that is useful for plant growth (Sheoran et al. 2010).

However, the shortage of topsoil attributing to the loss while hauling soil results in the difficulty of rehabilitation in some cases. Furthermore, soil erosion caused by heavy rain in the tropical climate in South-East Asian countries causes the loss of topsoil as shown in Figure 1, leading to the failure of rehabilitation (Sheoran et al. 2010). Therefore, it is important to secure enough amount of topsoil for rehabilitation in coal mining in South-East Asian countries. 


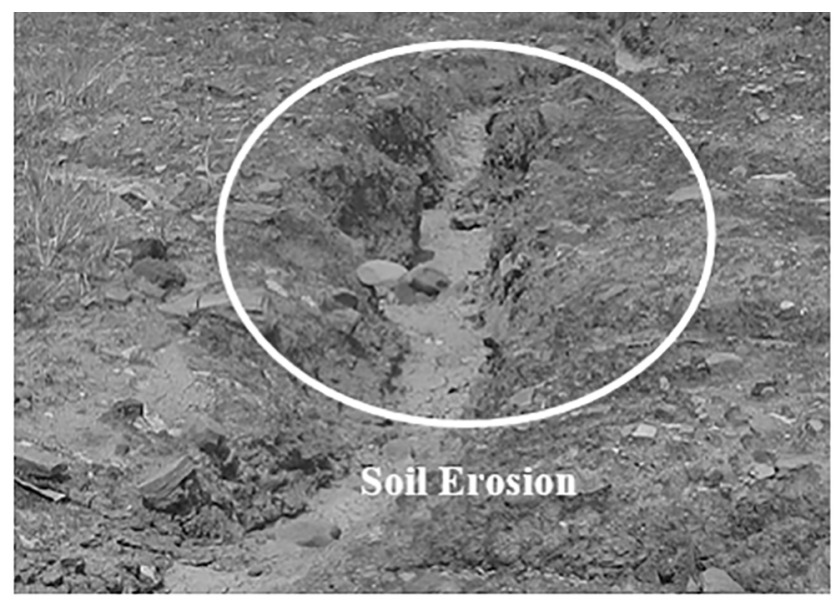

Figure 1: Soil erosion by heavy rain in rehabilitation area in coal mine in South East Asia country.

\subsection{Utilization of fly ash (FA) for secure of topsoil}

In order to secure the amount of topsoil, fly ash (FA), which is considered industrial waste after thermal electric power generation with coal was mixed in topsoil in the past research (Hamanaka et al. 2014). The amount of topsoil was successfully increased by mixing FA in topsoil without soil erosion by rainfall (Gorman et al. 2000, Matsumoto et al. 2016). Although FA has been utilized with the aim of increasing the amount of topsoil in several cases, the effects of metals in FA and the high alkalinity are concerned in terms of the inhibition of plant growth (Mahlaba et al. 2012, Cheng 2003). The effects have to be elucidated for securing the amount of topsoil by mixing FA.

In this study, the effects of FA in topsoil on the growth of plants were investigated, aiming at securing topsoil by mixing FA for effective rehabilitation in coal mining in South-East Asian countries.

\section{METHODS}

\subsection{Samples}

Topsoil was prepared by mixing the decomposed granite produced by the Gulin Kita-Kyu Co., Ltd., and the Kyushu Bentonite produced by the Shinagawa Yogyo Co., Ltd. based on the soil composition which was reported in post-mine land in open-pit coal mine in Indonesia (Matsumoto et al. 2016). The soils were classified as sand, silt, and clay after screening, followed by the preparation of the topsoil. Besides, fly ash (FA) taken in the coal fired power plant in Japan 
was mixed in the topsoil at the mixing ratio of $0 \%, 20 \%, 40 \%, 60 \%$, and $80 \%$, aiming at increasing the amount of topsoil. The topsoil with FA were homogeneously mixed by the cone and quartering method. They were labeled as FA0\%, FA20\%, FA40\%, FA60\%, and FA $80 \%$, and utilized for plant experiment after physical and chemical analysis of the topsoil in addition to FA as described as below.

\subsection{Plant experiment}

In this study, Acacia mangium which inhabits tropical forest in South East Asian countries was planted on the topsoil mixed with FA as indicated in section 2.1 in order to elucidate the effects of FA in topsoil on the growth of plants: the seeds were obtained in Japan. Acacia mangium has ever been successfully applied in post-mine lands for bauxite, copper, coal, and iron in the world, and widely utilized for a primary reclamation of post-mine land in many cases as shown in Figure 2 (Leon et al. 2013). It also can grow under the various conditions, such as in compacted soils, dry area, and humid area.

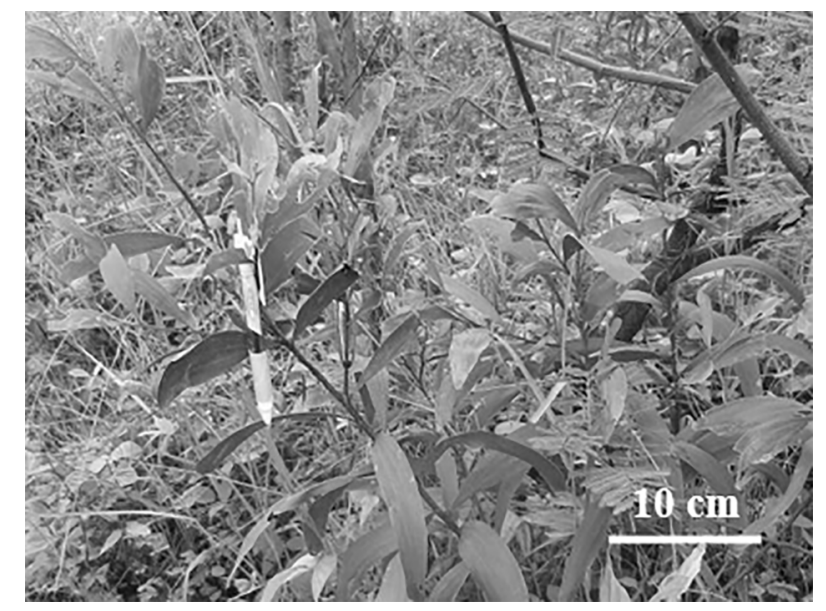

Figure 2: Acacia mangium in rehabilitation area in the coal mine in Indonesia.

Acacia mangium was planted on the prepared topsoil for 133 days until a clear distinction is observed in the phytotron glass room G-9 in Biotron Application Center, Kyushu University under the conditions as follows: at $30^{\circ} \mathrm{C}$ and $70 \%$ of relative humidity assuming the local climate in the coal mine in Indonesia. In this test, 5 plants were planted in pots by the mixing ratio of FA, and the height was measured every week. The growth rate was calculated with the change of height and the initial height $(8.0 \mathrm{~cm})$ of Acacia mangium every week. $500 \mathrm{~mL}$ of water was supplied to the pots every 3-4 days. The liquid fertilizer HYPONeX-R (N-P-K =6-10-5) diluted to $1,000 \mathrm{mg} / \mathrm{L}$ with deionized water was, moreover, added to them weekly to promote the growth. The leachate from the bottom of the pots was sampled to report the change of $\mathrm{pH}$. At 
the end of the experiment, the plants were taken to supply to the dissolution analysis with acids as described in section 2.4 for the purpose of understanding the effects of metal concentration in plant body on plant growth. In this study, the leaves, stem, and root were mixed and supplied to the dissolution analysis since it was unable to separate the samples in each part.

\subsection{Physical analysis}

The topsoil was supplied to the particle size distribution test (ASTM D422-63 2007), and the constant head permeability test (ASTM D 2434-68 2006) after the application of FA in the topsoil by reference to the standard of ASTM in order to understand the effects of physical conditions of the topsoil on the growth of Acacia mangium.

\subsection{Chemical analysis}

The FA was supplied to X-ray Fluorescence (XRF) analysis to measure the metal content in FA. The result was compared to that of FA produced in the coal fired power plant in the Indonesian mine.

The plant samples were taken at the end of the plant experiment, and washed with deionized water with the washing process using a sonication (UT-106H, SHARP) at room temperature so as to remove soil particles. They were dried at $60^{\circ} \mathrm{C}$ for 72 hours and pulverized using mortar and pestle. $5 \mathrm{~mL}$ of $61 \%$ nitric acid $\left(\mathrm{HNO}_{3}\right)$ and $35 \%$ hydrochloric acid $(\mathrm{HCl})$ mixed at volumetric ratio of $3: 1$ was added into $0.25 \mathrm{~g}$ of the plant samples by reference to the past study (Quadir et al. 2011). After the dissolution process, the solution was supplied to DigiPREP Jr. (SCP Science, Quebec, Canada) at $110^{\circ} \mathrm{C}$ until the samples were completely dissolved. In the case of obtaining undissolved samples in acids after the above process, $1 \mathrm{~mL}$ of the acids was added and the dissolution process was repeated. The volume of the solution was adjusted to 20 $\mathrm{mL}$ by adding deionized water, followed by the measurement of metal content using ICP-AES (VISTA-MPX ICP-OES (Seiko Inst., Japan)) after the filtration with $0.45 \mu \mathrm{m}$ of membrane filter. The concentration of $\mathrm{Al}, \mathrm{As}, \mathrm{B}, \mathrm{Fe}, \mathrm{Mn}, \mathrm{S}$, and $\mathrm{Zn}$ was measured, and it was calculated with mg per dry unit weight $(\mathrm{mg} / \mathrm{g})$ in this study. 


\subsection{Physical and chemical properties of the simulated topsoil mixed with fly ash}

The FA utilized in this study were composed of $67 \%$ of $\mathrm{Si}, 19 \%$ of $\mathrm{Al}, 4 \%$ of $\mathrm{Fe}$, and other elements such as $\mathrm{Ca}$ and $\mathrm{K}$ on the basis of the results of XRF analysis. Comparing the results with the metal content in FA which was taken in the coal fired power plant in the Indonesian mine, the content of $\mathrm{Al}$ in FA showed a similar value: the content of $\mathrm{Al}$ was $13-15 \%$ in FA in the Indonesian mine. It can be seen that the content of Al in the topsoil with FA rises with the increase of the mixing ratio of FA for the results. Considering that the inhibition of the growth of plants by aluminum was reported in the past research, the content of Al in FA may affect the growth of Acacia mangium in the plant experiment (Kochian et al. 2005).

Soil texture of the simulated topsoil is drawn at different mixing ratio of FA in Figure 3, and the permeability is shown in Figure 4. There is a close connection between a permeability of soil and the elongation of root of plants, and a permeability of soil is one of the important indicators to evaluate the effects of soil conditions on plant growth (Tangahu et al. 2011). Whereas the ratio of silt gradually rose with the increase of the mixing ratio of FA in the topsoil, the proportion of sand decreased in Figure 3. Additionally, the permeability of the topsoil decreased with the increase of the mixing ratio of FA. This was attributed to the increase of the composition of silt which showed low permeability compared to that of sand with the mixture of FA. Although the significant change of permeability of soils can affect the growth of plants, the growth of plants was not affected by the physical conditions, such as soil texture and permeability, in this study due to the minor change of the permeability: the change was reported within $3.0 \times 10^{-4} \mathrm{~cm} / \mathrm{s}$.

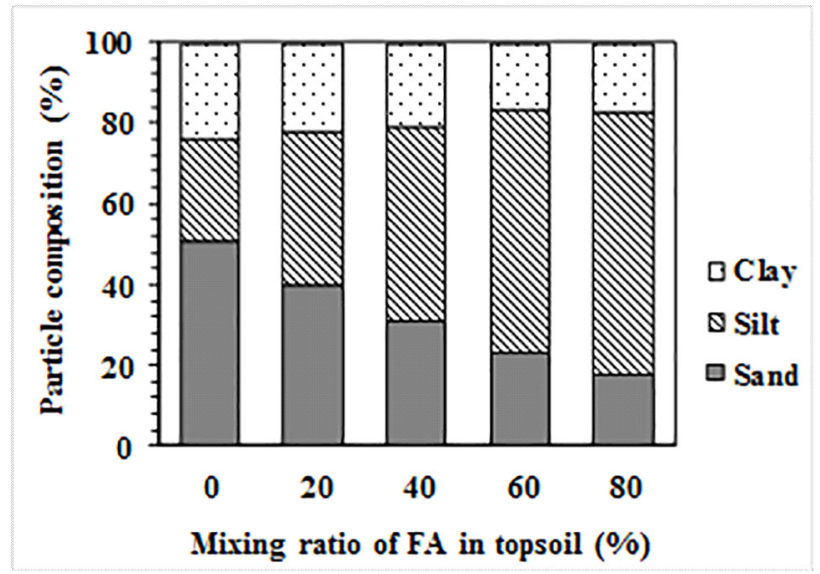

Figure 3: Soil texture at different mixing ratio of FA in the topsoil. 


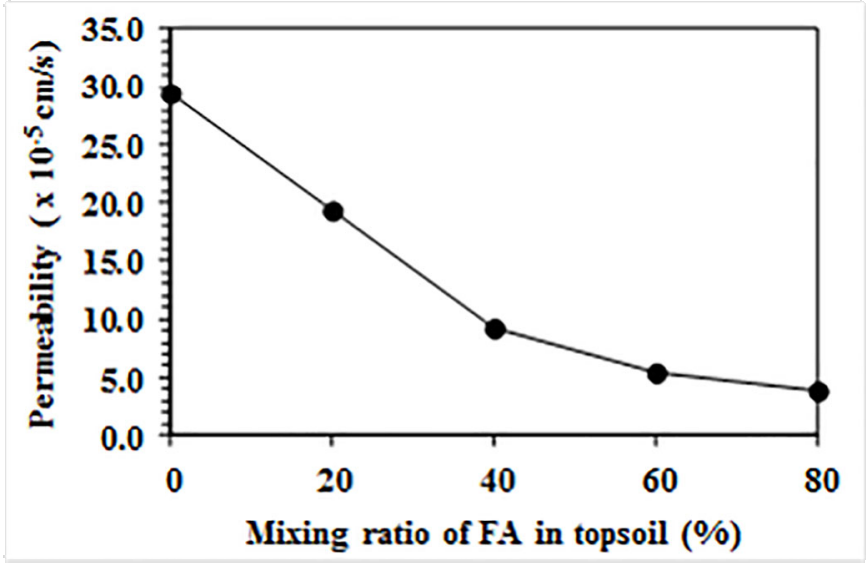

Figure 4: Permeability at different mixing ratio of FA in thetopsoil.

In short, there was not significant effect of physical conditions of the topsoil on the growth of Acacia mangium during the plant experiment. It can be, therefore, expected that the difference of the growth rate of Acacia mangium was attributable to the mixing ratio of FA.

\subsection{Plant growth of Acacia mangium on the simulated topsoil mixed with fly ash}

Figure 5 shows the change of growth rate of Acacia mangium for 133 days at different mixing ratio of FA in the plant experiment. The growth rate decreased with the increase of the mixing ratio of FA in the results. There was stagnation in the change of the growth rate at the mixing ratio of over $40 \%$ of FA. Besides, all of Acacia mangium were died after 28 days at the mixing ratio of over $80 \%$ of FA, resulting from the mixture of FA in topsoil.

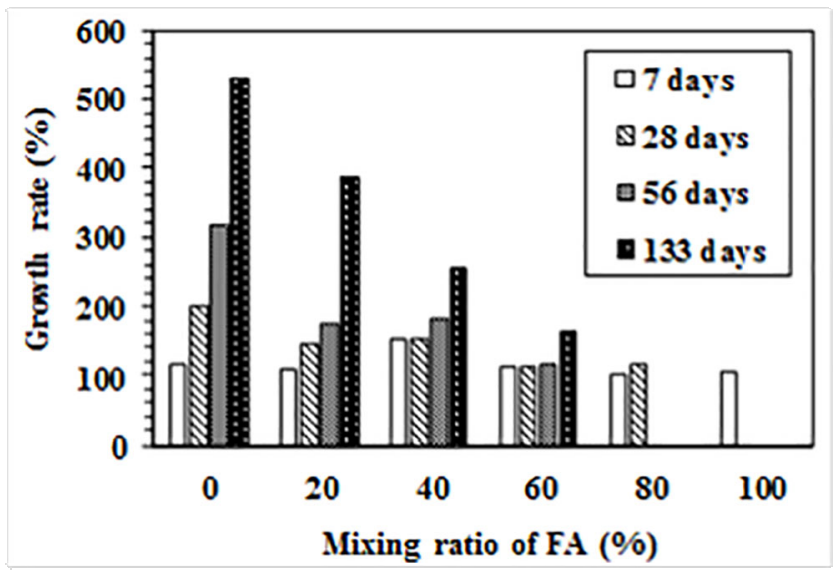

Figure 5: Growth rate of Acacia mangium at different mixing ratio of FA.

In addition, the $\mathrm{pH}$ in leachate was approximately 9.0 in the topsoil with the mixture of FA, although it was 7.5 without FA. The pH in leachate continued to show ca. 8.0 in topsoil with FA 
after 50 days, indicating that the mixture of FA in topsoil resulted in the alkali conditions in the leachate in consideration of the $\mathrm{pH}=7.5$ in the topsoil without FA. FA has a high alkalinity in the form of $\mathrm{CaO}$ (Pradhan \& Deshmukh 2008), and the content of $\mathrm{Ca}$ was observed in XRF analysis, resulting in the alkali conditions. Moreover, Figure 6 describes the concentration of A1 in the body of Acacia mangium, which was measured by the dissolution analysis with acids. The results showed that the concentration of $\mathrm{Al}$ was more than $1.8 \mathrm{mg} / \mathrm{g}$ at the mixing ratio of more than $40 \%$ of FA, whereas it was less than $0.6 \mathrm{mg} / \mathrm{g}$ in the topsoil at the mixing ratio of less than $20 \%$. Aluminum exists as $\mathrm{Al}(\mathrm{OH})_{3}$ which is an insoluble mineral at neutral condition (ca. $\mathrm{pH}=7.0)$; meanwhile, it is released as $\mathrm{Al}(\mathrm{OH})_{4}{ }^{-}$at alkali condition: aluminum dissolves as $\mathrm{Al}(\mathrm{OH})_{4}{ }^{-}$at ca. $\mathrm{pH}=9.0$ (Matsumoto 2000). Aluminum inhibits the elongation of roots of plants (Kochian et al. 2005, Kikui et al. 2005), suggesting that Al in the topsoil derived from FA dissolved under the alkali condition and were concentrated in the body of Acacia mangium along with the inhibition of the growth at the mixing ratio of over $40 \%$ of FA. In FA20\% sample, the concentration of $\mathrm{Al}$ in the plant body was, however, lower than that of FA40\%-80\% since the amount of dissolved $\mathrm{Al}$ from FA was not higher than that of FA40\%-80\% due to the low mixing ratio of FA. For these results, the mixing ratio of FA with the aim of increasing the amount of topsoil without the inhibition of plant growth should be adjusted at the mixing ratio of less than $20 \%$ of FA in this study in terms of the concentration of $\mathrm{Al}$ in the body of plants. Furthermore, the content of $\mathrm{Al}$ in FA in this study showed a similar value with that of FA which is produced in the Indonesian mine, indicating that the utilization of FA for the purpose of increasing the amount of topsoil may result in the inhibition of plant growth due to the effects of $\mathrm{Al}$ in open-pit coal mines in South East Asian countries.

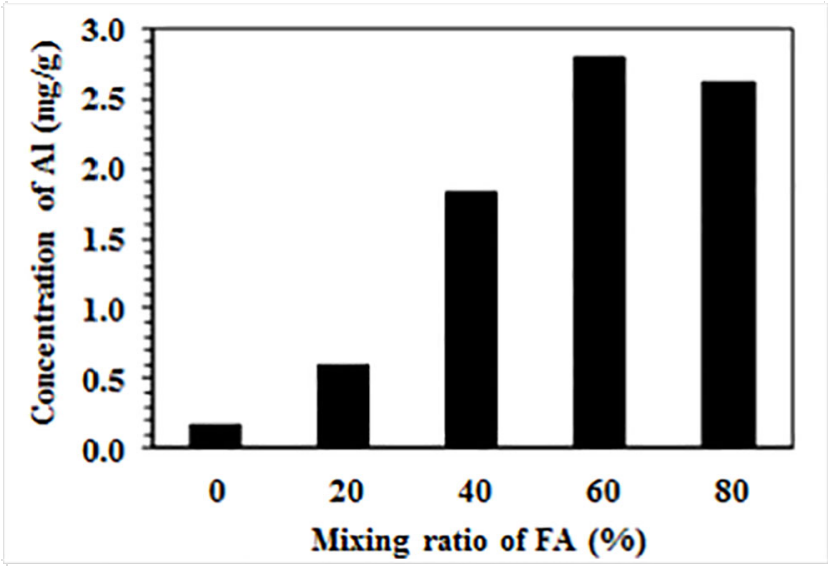

Figure 6: Concentration of Al in the body of Acacia mangium after the plant experiment at different mixing ratio of $F A$. 
However, since the tolerance to $\mathrm{Al}$ in plants varies depending on the plant species and the chemical composition of FA depends on the quality of coal, additional experiment with other species of plants and coal is required in order to establish the guideline of the utilization of FA in topsoil to secure the enough amount of topsoil.

\section{CONCLUSIONS}

In this study, the application of fly ash (FA) to topsoil was evaluated in terms of the effects of FA on the growth of Acacia mangium, aiming at securing topsoil in open-pit coal mines. The results obtained by the experiments are summarized as follows:

(1) The FA in this study was composed of a large amount of silt. Therefore, the permeability of the topsoil decreased with the increase of the mixing ratio of FA in topsoil. However, there was not significant effect of physical conditions of the topsoil on the growth of plants due to the minor change of the permeability: the change was reported within $3.0 \times 10^{-4} \mathrm{~cm} / \mathrm{s}$.

(2) The FA in this study consisted of $67 \%$ of $\mathrm{Si}, 19 \%$ of $\mathrm{Al}, 4 \%$ of $\mathrm{Fe}$, and other elements such as $\mathrm{Ca}$ and $\mathrm{K}$.

(3) There was stagnation in the change of the growth rate at the mixing ratio of over $40 \%$ of FA. Besides, all of Acacia mangium were died after 28 days at the mixing ratio of over $80 \%$ of FA, resulting from the addition of FA in topsoil.

(4) The concentration of $\mathrm{Al}$ was more than $1.8 \mathrm{mg} / \mathrm{g}$ at the mixing ratio of more than $40 \%$ of FA, whereas it was less than $0.6 \mathrm{mg} / \mathrm{g}$ in the topsoil at the mixing ratio of less than $20 \%$. Considering that the $\mathrm{pH}$ in leachate was approximately 9.0 in the topsoil with the mixture of FA, Al in the topsoil derived from FA dissolved under the alkali condition and were concentrated in the body of Acacia mangium along with the significant inhibition of the growth at the mixing ratio of over $40 \%$ of FA. Therefore, FA has to be utilized in topsoil at the mixing ratio of less than $20 \%$ of FA in order to increase the amount of topsoil in this study in terms of the concentration of $\mathrm{Al}$ in the body of plants.

(5) The content of Al in FA in this study showed a similar value with that of FA which is produced in the Indonesian mine, indicating that the utilization of FA for the purpose of increasing the amount of topsoil may result in the inhibition of plant growth due to the effects of Al in open-pit coal mines in South East Asian countries. 


\section{ACKNOWLEDGEMENT}

The FA samples were obtained in the coal fired plant in Japan, and the authors are grateful to the plant for providing the samples. We also would like to express our appreciation to the Biotron Application Center, Kyushu University for plant experiment.

\section{REFERENCES}

American Society for Testing and Materials (ASTM). (2006) ASTM Standard D 2434-68, Standard Test Method for Permeability of Granular Soils, ASTM.

American Society for Testing and Materials (ASTM). (2007) ASTM Standard D422-63(2007)e2, Standard Test Method for Particle-size Analysis of Soils (withdrawn 2016), ASTM.

Cheng, S. (2003) Effects of heavy metals on plants and resistance mechanisms. A state-of-the-art report with special reference to literature published in Chinese journals. Environ. Sci. Pollut. Res. Int. 10(4), 256-264.

Gorman, J.M. \& Sencindiver, J.C. \& Horvath, D.J. \& Singh, R.N. \& Keefer, R.F. (2000) Erodibility of fly ash used as a topsoil substitute in mineland reclamation. J. Environ. Qual., 29(3), 805-811.

Hamanaka, A. \& Inoue, N. \& Matsumoto, S. \& Shimada, H. \& Sasaoka, T. \& Matsui, K. \& Miyajima, I. (2014) Rehabilitation of Open Cut Coal Mine with Paper Mulberry (Broussonetia papyrifera) in Indonesia. J. of the Polish Mineral Engineering Society 15(2), 159-163.

Kikui, S. \& Sasaki, T. \& Maekawa, M. \& Miyao, A. \& Hirochika, H. \& Matsumoto, H. \& Yamamoto, Y. (2005) Physiological and genetic analyses of aluminium tolerance in rice, focusing on root growth during germination. J. of Inorganic Biochemistry 99(9), 1837-1844.

Kochian, L.V. \& Pineros, M.A. \& Hoekenga, O.A. (2005) The physiology, genetics and molecular biology of plant aluminum resistance and toxicity. Plant Soil 274, 175-195.

Leon, J.D. \& Castellanos, J. \& Casamitjana, M. \& Osorio, N.W. \& Loaiza, J.C. (2013) Hai, R. (ed.), Alluvial gold-mining degraded soils reclamation using Acacia mangium plantations: an evaluation from biogeochemistry, 155-176. New York: Nova Science.

Mahlaba, J.S. \& Kearsley, E.P. \& Kruger, R.A. (2012) Microstructural and mineralogical transformation of hydraulically disposed fly ash - implications to the environment. Coal Combustion and Gasification 4, 21-27.

Matsumoto, H. (2000) Plant responses to aluminum stress in acid soil molecular mechanism of aluminum injury and tolerance. Kagaku to Seibutsu 38(7), 425-458. 
Matsumoto, S. \& Ogata, S. \& Shimada, H. \& Sasaoka, T., Kusuma, J.G. \& Gautama, S.R. (2016) Application of coal ash to postmine land for prevention of soil erosion in coal mine in Indonesia: utilization of fly ash and bottom ash. Advances in Materials Science and Engineering 2016, 1-8.

Pradhan, A. \& Deshmukh, J.P. (2008) Utilization of fly ash for treatment of acid mine water. J. of Environmental Research and Development 3(1), 137-142.

Quadir, Q.F. \& Watanabe, T. \& Chen, Z. \& Osaki, M. \& Shinano, T. (2011) Ionomic response of Lotus Japonicus to different root-zone temperatures. Soil Science and Plant Nutrition 57, 221-232.

Sheoran, V. \& Sheoran, A.S. \& Poonia, P. (2010) Soil reclamation of abandoned mine land by revegetation: a review. Int. J. Soil, Sediment and Water 3(2), 1-21.

Tangahu, B.V. \& Sheikh Abdullah, S.R. \& Basri, H. \& Idris, M. \& Anuar, N. \& Mukhlisin, M. (2011) A review on heavy metals $(\mathrm{As}, \mathrm{Pb}$, and $\mathrm{Hg}$ ) uptake by plants through phytoremediation. Int. J. Chem. Eng. 2011, 1-31. 